\title{
Abutilon ornamental (Abutilon sp. - Malvaceae) mostrando pústulas de Synchytrium australe.
}

\author{
Mário Barreto Figueiredo ${ }^{1,2}$, Leila Nakati Coutinho ${ }^{1}$, Christiane Ceriani Aparecido ${ }^{1,3}$, Martha Maria Passador ${ }^{1}$
}

${ }^{1}$ Laboratório de Micologia Fitopatológica, Instituto Biológico de São Paulo, e-mail: figueiredo@biologico.sp.gov.br, CP 18989, CEP, São Paulo, SP; ${ }^{2}$ Bolsista CNPq - Produtividade em Pesquisa; ${ }^{3}$ Bolsista FAPESP - Doutoramento (Proc. 01/13306-3)

Autor para correspondência: Mário Barreto Figueiredo

Data de chegada: 30/09/2004. Aceito para publicação em: 02/10/2006.

\section{RESUMO}

Figueiredo, M.B., Coutinho, L. N., Aparecido, C.C., Passador, M.M. Abutilon ornamental (Abutilon sp. - Malvaceae) mostrando pústulas de Synchytrium australe. Summa Phytopathologica, v.33, n.2, p.195-198, 2007.

Plantas de abutilon recebidas para análise fitopatológica pelo Instituto Biológico, São Paulo, Brasil mostrando como sintomas pústulas semelhantes a ferrugem (Uredinales) sobre folhas e caule foram estudadas para determinar o agente causal. Numerosos esporângios amarelos característicos de fungos zoospóricos pertencentes à Ordem Chytridiales foram encontrados no interior de galhas superficiais. Com base no estudo de KARLING (1955), o patógeno foi identificado como Synchytrium australe Speg. O material foi herborizado e armazenado no Herbário Micológico do Instituto Biológico sob o número IBI/SP 11975. Esta foi a primeira constatação desta espécie no Brasil.

Palavras-chave adicionais: Chytridiales, planta ornamental

\section{ABSTRACT}

Figueiredo, M.B., Coutinho, L. N., Aparecido, C.C., Passador, M.M. Figueiredo, M.B., Coutinho, L. N., Aparecido, C.C., Passador, M.M. Pustules on stems, leaves and pods of ornamental abutilon (Abutilon sp.) caused by Synchytrium australe. Summa Phytopathologica, v.33, n.2, p.195-198, 2007.

The genus Abutilon includes a large number of ornamental species with nice foliage and flowers. The different species are known under several common names as Indian mallow, China jute, butterprint, etc. Plants of abutilon received for phytopathological analysis by the Instituto Biologico, São Paulo, Brazil showing curious rust like symptoms (pustules) on leaves, stems and pods were studied to determine the causal agent.
Numerous yellow sporangia characteristic of zoosporic fungi belonging to the Order Chytridiales were found within the superficial intact galls. Based on KARLING (1955) paper the pathogen was identified as Synchytrium australe Speg. The voucher material was saved and settled in the Mycological Herbarium of the Institution under the number IBI/SP 11975. This was the first report of the occurrence of this species in Brazil.

Additional keywords: Chytridiales, ornamental plant

O gênero Abutilon inclui um grande número de espécies ornamentais conhecidas sob vários nomes populares como sininho, chapéu-decardeal (A. megapotanicum St. Hil. \& Naud.), lanterna chinesa ( $A$. striatum Dicks), etc. São arbustos de estrutura semi-lenhosa, eretos, ramificados, chegando, às vezes, de dois a três metros de altura, com folhagem e flores ornamentais (8).

Em maio de 2004, o Laboratório de Micologia Fitopatológica do Centro de Pesquisa e Desenvolvimento de Sanidade Vegetal (CPDSV), recebeu materiais de Abutilon provenientes do município de Guarujá, SP, com grande número de galhas, resultantes de hiperplasia e hipertrofia dos tecidos, que atingiam o caule e as folhas, lembrando pústulas causadas por insetos. Em condições de umidade e água no estado líquido, as pústulas rompiam, liberando um grande número de esporos amarelos, microscopicamente semelhantes à forma ecial de ferrugens (Uredinales) (Figura 1).

Estudos mais detalhados, sob microscopia óptica e de contraste de fase, revelaram tratar-se de um fungo zoospórico da Ordem Chytridiales, pertencente ao gênero Synchytrium. As observações realizadas foram documentadas por meio de câmara digital (Figura 3 -
1, 2, 3 e 4). A facilidade na determinação do gênero deveu-se a experiência anterior, na determinação de sua ocorrência sobre siratro (Macropitilium atropurpureum D. C.) (9). A fase vegetativa dos fungos dessa ordem varia em aparência, mas sempre produzem zoósporos com flagelo posterior.

Entre os fungos zoospóricos, a Ordem Chytridiales, a qual pertence o gênero Synchytrium é, segundo DAYAL, 1997 (in 10), a mais complexa e os critérios taxonômicos adotados não são, até hoje, muito bem definidos. Algumas características de importância taxonômica podem se alterar de tal forma em substratos naturais, que alguns gêneros podem ser classificados em mais de uma família ou subgênero. Conseqüentemente, a instabilidade de algumas características torna difícil a classificação dos mesmos. Os critérios taxonômicos usados na identificação e classificação de quitrídios incluem: a)- tamanho, forma, ultraestrutura e pigmentação do zoósporo; b)- organização do talo; c)- método de desenvolvimento do talo; d)- morfologia geral do talo e das estruturas reprodutivas; e)- tipo de reprodução sexual; f)- modo de germinação do ovo ou zigoto e do esporo de resistência; g)- relação com o substrato e h)- 

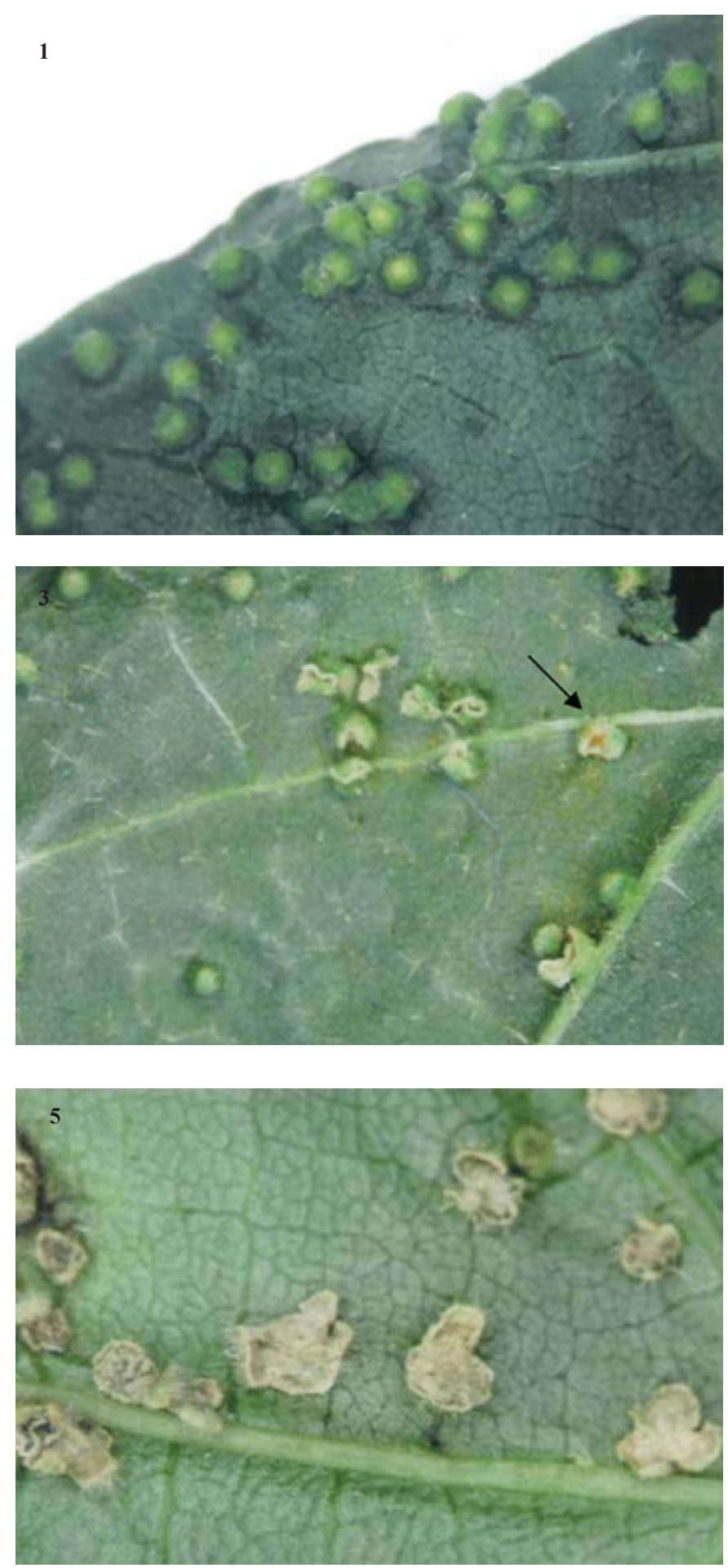

especificidade do hospedeiro (gênero ou família) para as espécies parasitas.

O gênero Synchytrium inclui mais de 100 espécies parasitas de plantas fanerogâmicas. Estes são fungos endofíticos e holocárpicos, com esporângios inoperculados. Nesse gênero, o talo forma colônias e divide-se em vários órgãos reprodutivos (esporângios e gametângios), que são envolvidos por uma membrana comum, formando um soro (2). Esse gênero foi intensiva e extensivamente estudado por KARLING $(3,4,5,6)$, que o subdividiu em seis subgêneros, conforme o ciclo de vida dos mesmos. Infelizmente, até hoje são conhecidos, em detalhes, os ciclos vitais de, apenas,
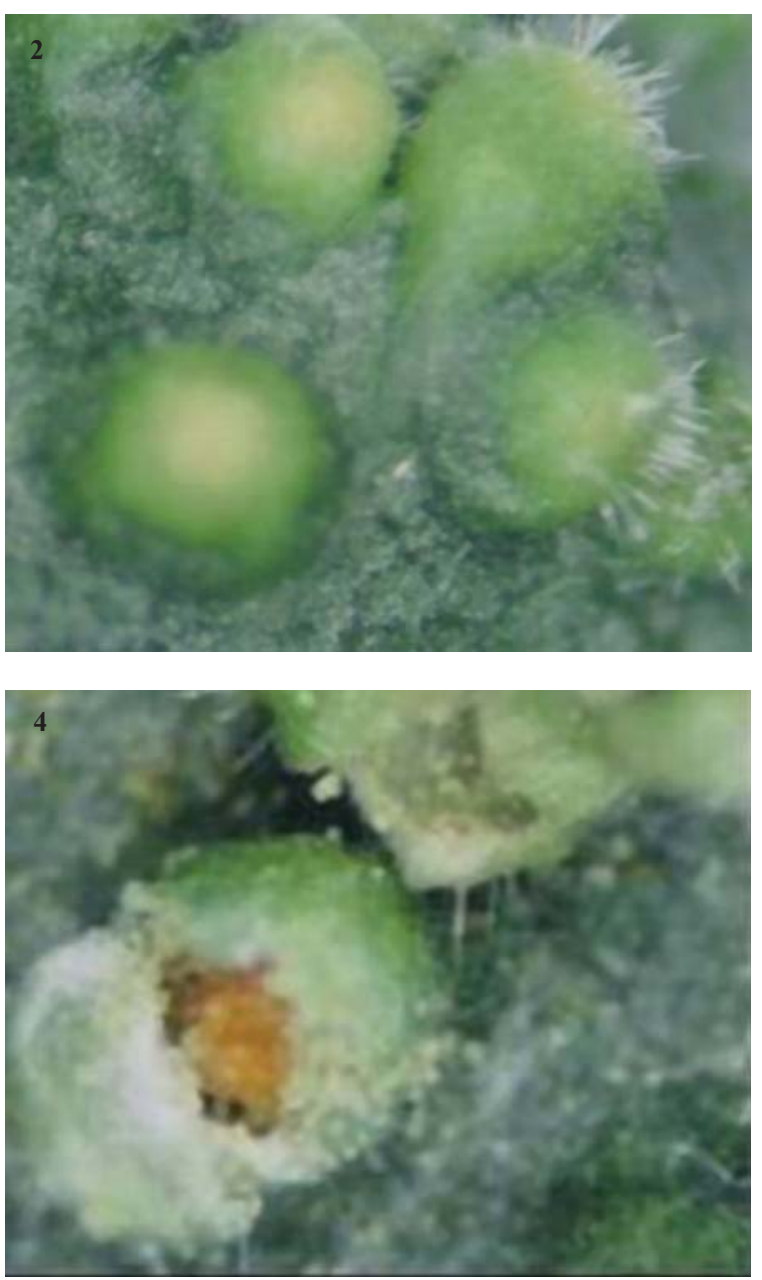

Figura 1. Pústulas de Synchytrium sobre folhas de Abutilon observadas sob estereomicroscópio. 1- Pústulas ou galhas jovens de Synchytrium australe sobre folha de Abutilon sp. 2- Pústulas de Synchytrium australe em vias de maturação. 3- Pústulas ou galhas rompidas, mostrando esporângios amarelos (seta). 4Detalhe de uma pústula rompida, mostrando esporos de resistência (esporângios ou gametângios) com pigmentação amarela. 5- Galhas totalmente rompidas e livres de esporângios.

algumas poucas espécies. Entre essas espécies o ciclo de vida mais bem conhecido é o do Synchytrium endobioticum (Schilberszky) Persival, agente causal da sarna negra da batata (Solanum tuberosum L.), doença importante nos países de clima temperado do Hemisfério Norte. Esta doença ocorre, circunstancialmente, em nosso país em amostras de batata importadas (batatas semente), mas as nossas condições climáticas não permitem seu desenvolvimento e dispersão.

Para a identificação da espécie de Synchytrium sobre as plantas recebidas (abutilon), foi tomado como base o trabalho de KARLING (4). Segundo este autor, o gênero Synchytrium é o maior gênero da 

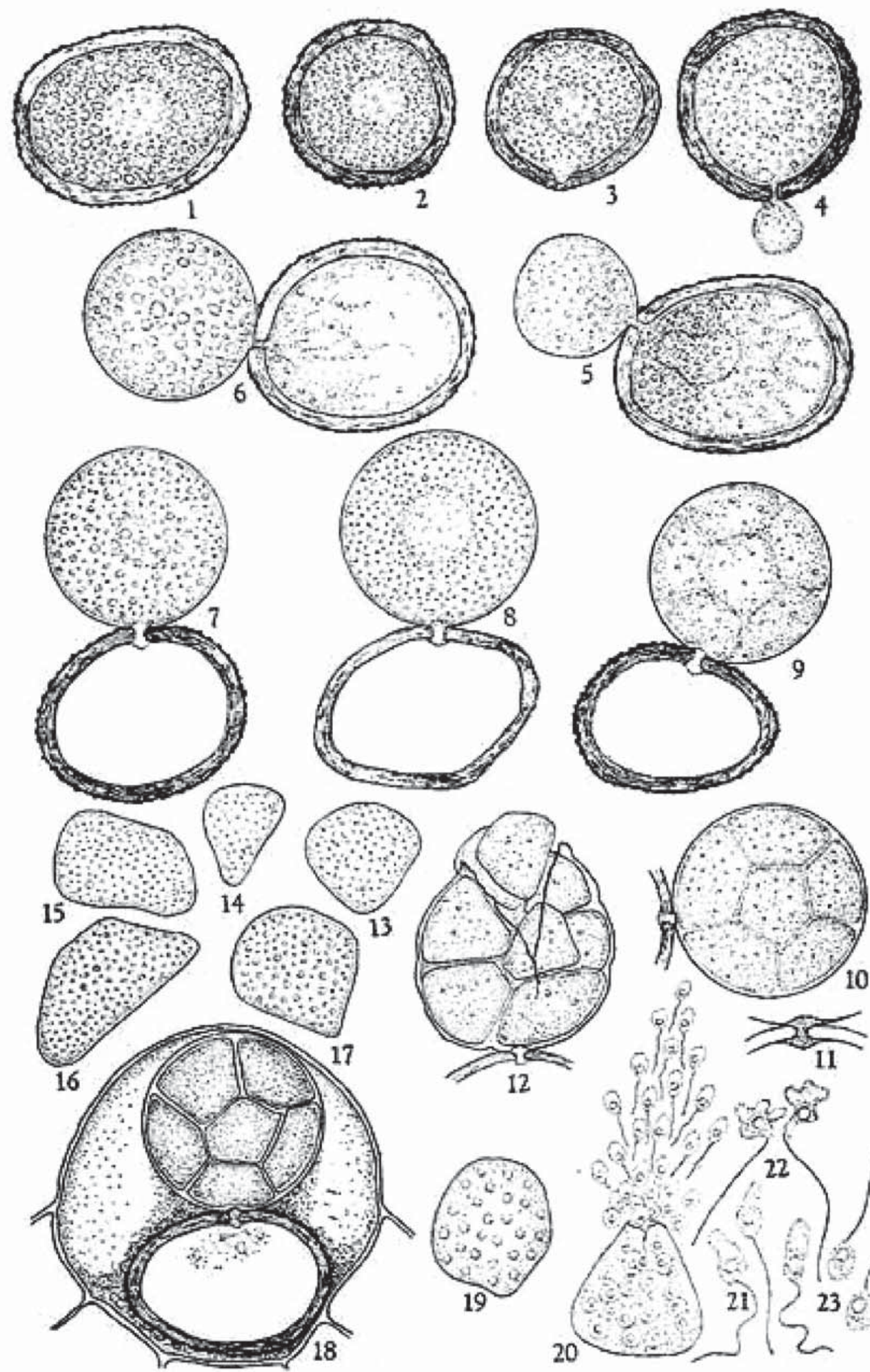

2

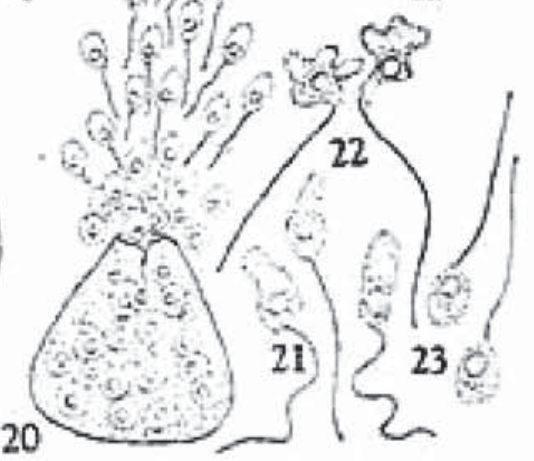

Figs. 1-23.

Figura 2. Ilustração de Synchytrium australe sobre Malvaceae, de acordo com KARLING, Mycologia, 47: 185-192, 1955b. 1- Esporo de resistência maduro; 2 e 3- Estágios iniciais da germinação; 4 a 8- Estágios do desenvolvimento do soro; 9 e 10- Clivagem no interior do esporângio; 11- Batoque ou "rolha" do poro na parede do esporo de resistência; 12- Ruptura do soro; 13 a 17 e 19- Variações em tamanho e forma dos esporângios; 18- Germinação de um esporo de resistência no interior de uma galha intacta; 20- Deiscência do esporângio; 21 a 23- Zoósporos posteriormente uniflagelados. 

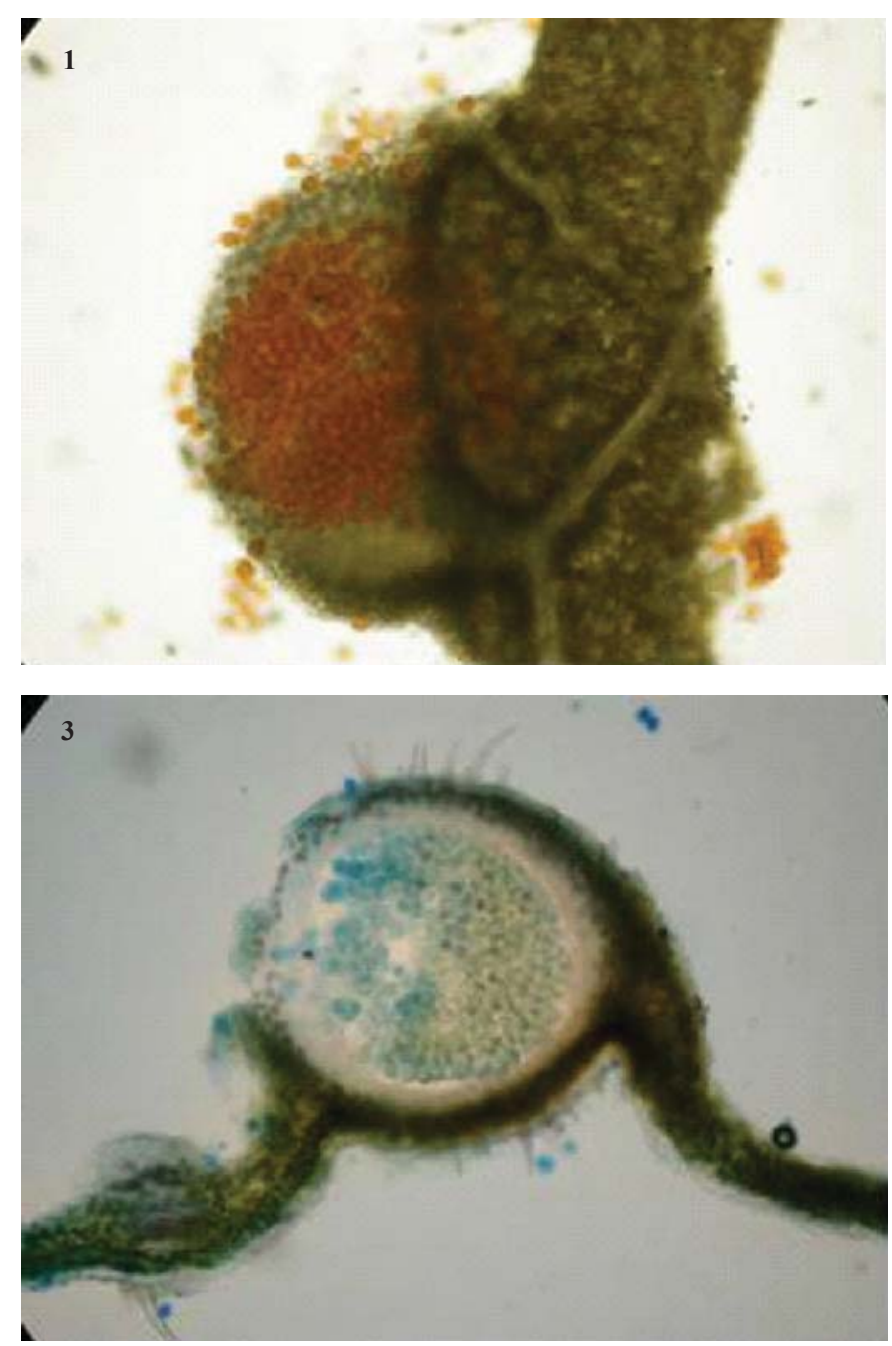

Figura 3. Synchytrium australe observado ao microscópio composto. 1,2 e 3 -Corte transversal de galhas presentes em folhas de abutilon, mostrando esporângios de Synchytrium australe. 4 - Esporos de resistência não germinados.

Ordem Chytridiales e abrange mais de 150 espécies, sendo todas parasitas de algas, musgos, samambaias (pteridófitas) e de plantas floríferas. Desde que este gênero foi estabelecido por DE BARY \& WORONIM em 1863 (1), a maioria dos pesquisadores tiveram a tendência de criar novas espécies para cada hospedeiro diferente que apresentasse infecção natural. Isto foi, particularmente, evidente na primeira metade do século XX (1940-1950), quando mais de 50 espécies foram descritas e criadas. Procurando corrigir esse procedimento, KARLING (4) estudou profundamente a espécie Synchytrium australe Speg. (sin. S. modioliensis M. T. Cook), através de inoculações experimentais sobre folhas tenras e emergentes de plantas adultas de 12 famílias e gêneros de plantas floríferas. Nestes estudos, apenas plantas da Família Malvaceae foram efetivamente infectadas, dentre as quais estavam plantas pertencentes ao gênero Abutilon. A Figura 2 adaptada de KARLING ilustra esta espécie.

Pelas características do fungo estudado foi possível identificálo como Synchytrium australe. O material recebido para análise, após os estudos, foi herborizado e armazenado no Herbário Micológico da Instituição sob o número IBI/SP 11975. A primeira identificação desse fungo na América do Sul foi feita por Spegazzini, sobre Modiola caroliniana (Malvaceae). Esta foi a primeira constatação de $S$. australe no Brasil.
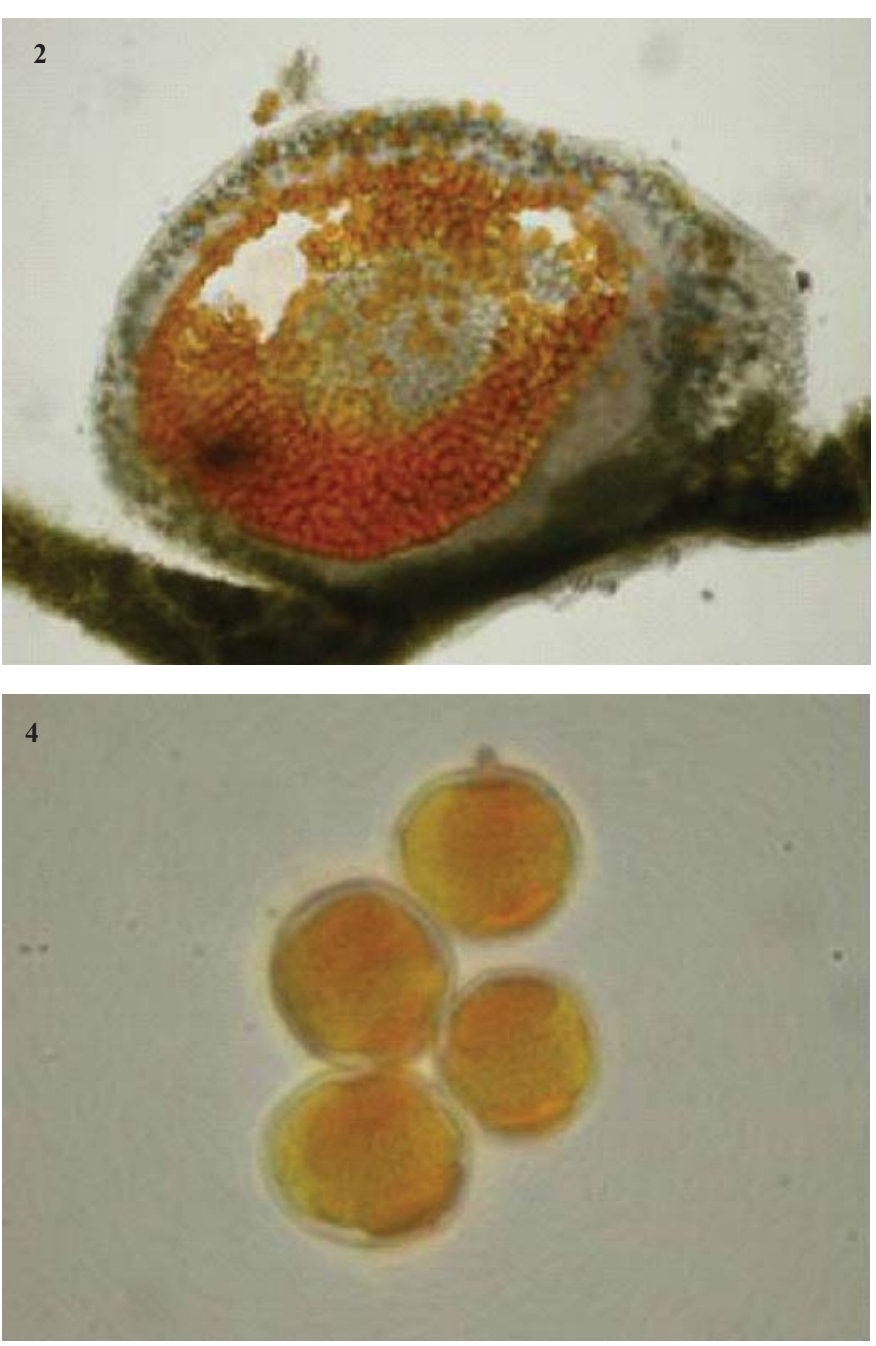

\section{REFERÊNCIAS BIBLIOGRÁFICAS}

1. Ainsworth \& Bysby's - Dictionary of the Fungi - Hawsworth, D.L.; Kirk, B.C. ; Suton, D.N. Pegler I.M.I. $8^{\circ}$. Ed. Cab. International 1995. $616 \mathrm{pp}$.

2..Alexopoulus, C.J.; Mims, C. W.; Blackwell, M. Introductory Mycology. $4^{\text {th }}$ ed. John Wiley: New York, 1996, 869p.

3..Karling, J. S. Host range of Synchytrium aecidioides. Sydowia, Innsbruck, v. 8, p. 355-359, 1954.

4..Karling, J. S. Hosts of Synchytrium autrale Speg. Sydowia Annales Mycologici, Goteborgs, v. 9, p. 441-450, 1955a.

5..Karling, J. S. Resting spore germination in Synchytrium australe in relation to its classification. Mycologya, Albuquerque, v. 47, p. $185-192,1955 \mathrm{~b}$.

6. Karling, J. S. Synchytrium. New York: Academic Press, 1964, 470 p.

7. Kendrick, B. The fifth kingdow. Ed. Stan Brown: Ontário, 1985, $364 \mathrm{p}$.

8. Lorenzi, H.; Souza, H. M. Plantas ornamentais no Brasil. 3 ed. Nova Odessa: Instituto Plantarum. 2001, 1088 p.

9. Namekata, T.; Amaral, R. E. M.; Pitta, G. P. Figueiredo, M. B. Pústulas em hastes, folhas e vagens de seratro (Macroptilium atropurpureum, D. C.) causadas por fungo do gênero Synchytrium. O Biológico, São Paulo, v. 40, p. 233-236, 1974.

10. Souza Rocha, J. R. Fungos zoospóricos em área de Cerrado no Parque Nacional de Sete Cidades, Piauí, Brasil. 2002. 268p.Tese ( Doutorado em Ciências - Botânica) - Instituto de Biociências, Universidade de São Paulo, São Paulo. 